Criação / Vídeo 


\section{Tereza: a imagem eletrónica no tempo-espaço carcerário}

\section{MARCOS ERNESTO ROGATTO}

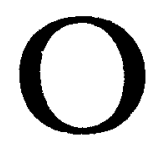

vídeo Tereza, ao retratar o cotidiano carcerário de uma maneira diferenciada, conseguiu captar um quadro fiel das relaçōes entre os presidiários e se tornou a produção independente mais premiada em festivais do país no ano passado. Mais que um mero registro, o trabalho revela os diversos elementos presentes no espaço privado das celas, sejam eles verbais ou imagéticos. Durante os $16 \mathrm{mi}$ nutos da fita encontramos uma estrutura que apresenta características tanto do documentário como da vídeo arte, procurando desvendar os códigos e leis internas, acrescentando efeitos digitais no espaço da tela, pensados e conjugados de maneira

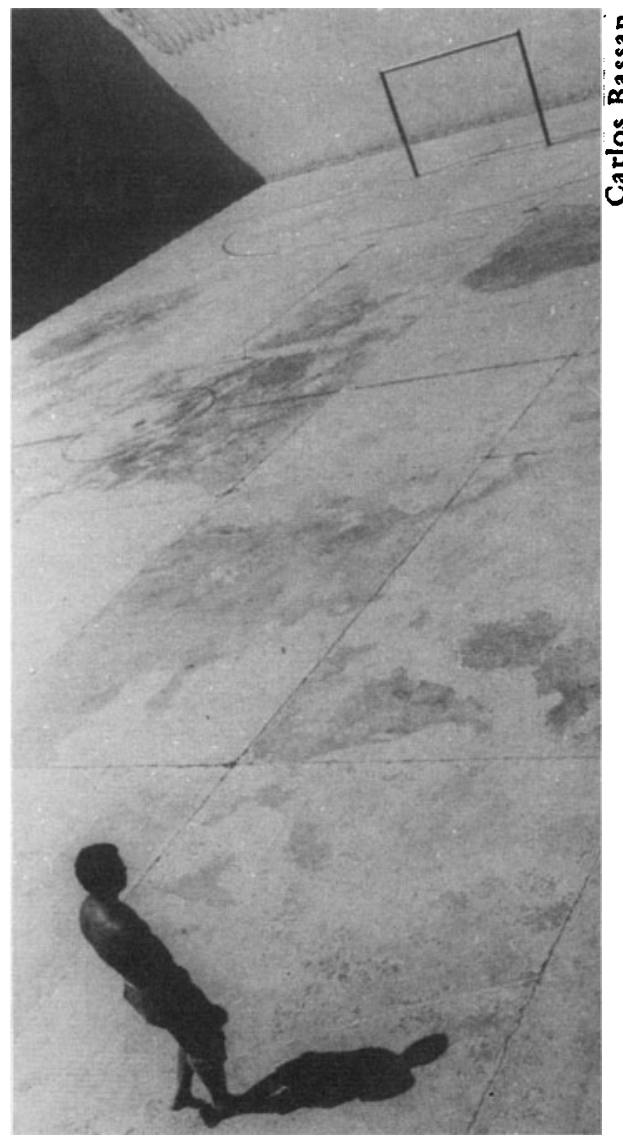

Preso circula pelo pátio da cadeia que náo estivessem presentes como simples artifícios de embelezamento.

A abordagem do tema por si só poderia dar margem à idéia de que a escolha do objeto focalizado seria suficiente para garantir o bom resultado da realizaçáo. Afinal, pela própria caraterística da produção independente, a palavra dos exclutidos ou exóticos é tema recorrente de outras produçóes premiadas. Porém, o que aponta para as diferenças desse vídeo, pode contribuir para justificar o seu reconhecimento.

O trabalho desenvolvido na pré-produção, através de rigorosas pesquisas e da convivência com os entrevistados - realizadas pelo antropólogo Kiko Goifman - fez emergir falas espontâneas, que demonstram outros aspectos desses espaços de reclusão e não os tradicionais evocados pelo tema, relacio- 


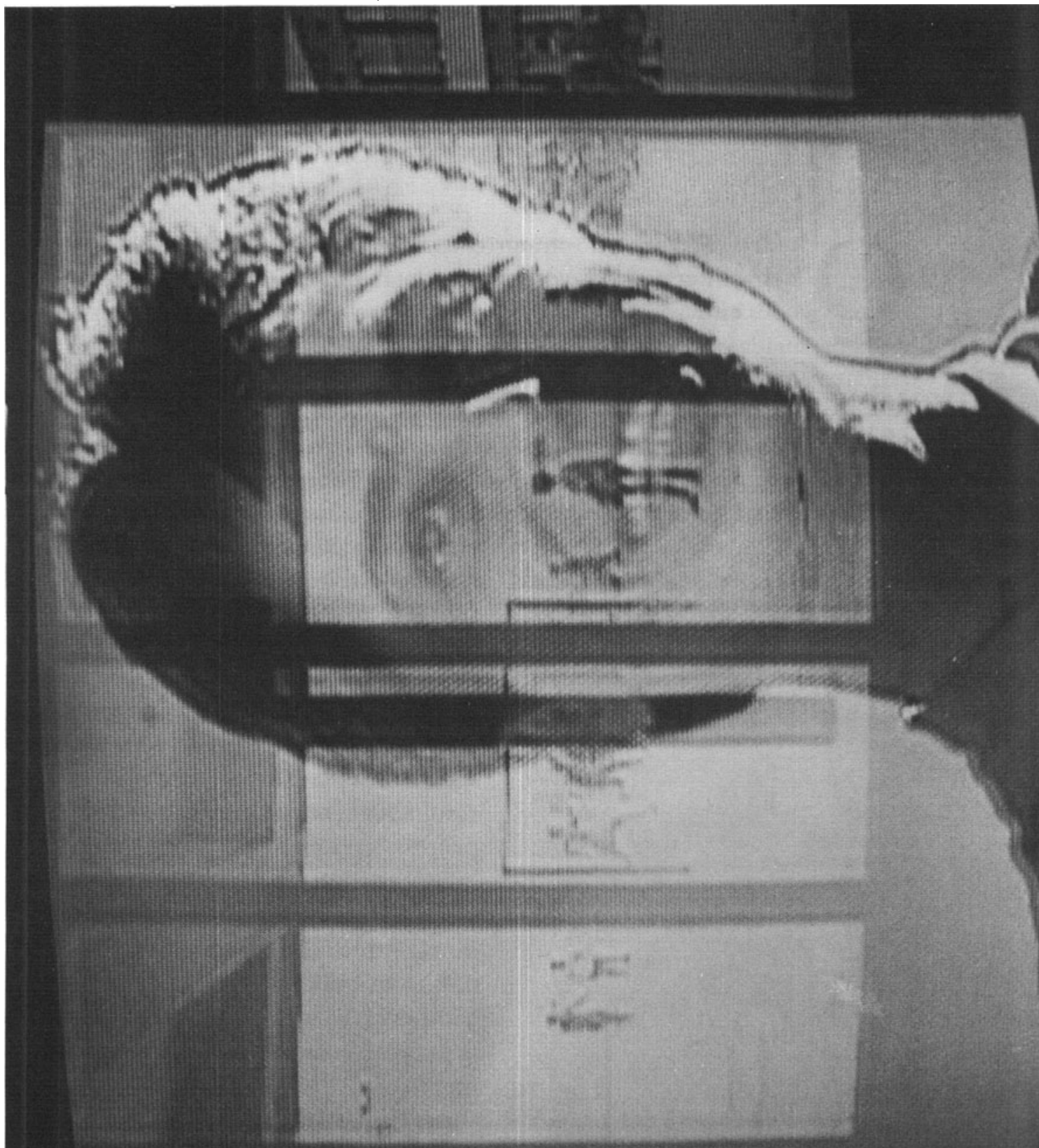

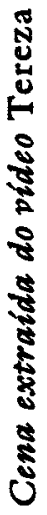


nados às condiçōes de carceragem e aos direitos humanos. Junto a isso, o tratamento das imagens na pós-produção, enxertando frases e fusóes referentes ao tema, buscava compor um resultado de congregar o experimento e a retrataçáo daquele particular universo de relaçóes.

Em um momento no qual cada vez mais o desenvolvimento tecnológico cria novos equipamentos, contribui para ligeirizar os trabalhos e aprimorar as formas de criação, o que às vezes se nota é um certo abuso na mediaçáo da técnica, em detrimento de uma postura de pesquisa e reflexão. É como se, ao querer desvendar aspectos de uma tribo indígena, acreditássemos que bastaria falar com o pagé pelo celular, redigir um texto no lap-top e mandar para a aldeia os últimos lançamentos do Primeiro Mundo.

Entre os competentes trabalhos dos realizadores brasileiros temos uma diversidade de experiências dentro da produçăo independente de vídeo. Mas, ao mesmo tempo, nota-se um certo deslumbramento com os botões, com excessivas inclusóes eletrônicas, que uma suposta modernidade impõe.

Não se trata de defender a linearidade em uma mera busca de depoimentos para encadeá-los em uma seqüência aparentemente lógica, acreditando que esse deva ser o formato dos documentários. Experiências com o fragmentário, a saturaçáo das imagens e a edição pontuada por efeitos digitais podem trazer resultados interessantes e contribuir com os novos formatos de realizaçáo e até com o aprimoramento dos programas de certas emissoras comerciais. É preciso ter em mente que não basta apenas a mediação tecnológica dos equipamentos como mero artifício na busca do diferenciado.

Ao não se limitar a uma coletânea de depoimentos e utilizar as interferências da tecnologia como um complemento das informaçóes visuais do sujeito retratado, o vídeo Tereza buscou revelar o pendor que a palavra congrega, em sua imbricação com as imagens trabalhadas do ambiente retratado.

Ficha técnica - Formato: U-Matic; Padraao de cor: NTSC; Direção: Goifman/Souza; Ediçăo: Goifman/Souza; Roteiro: Goifman/Rogatto; Produção: Pedrosa; Trilha Sonora: Cuidado que mancha; Produtora: Studio Eletrônico. 


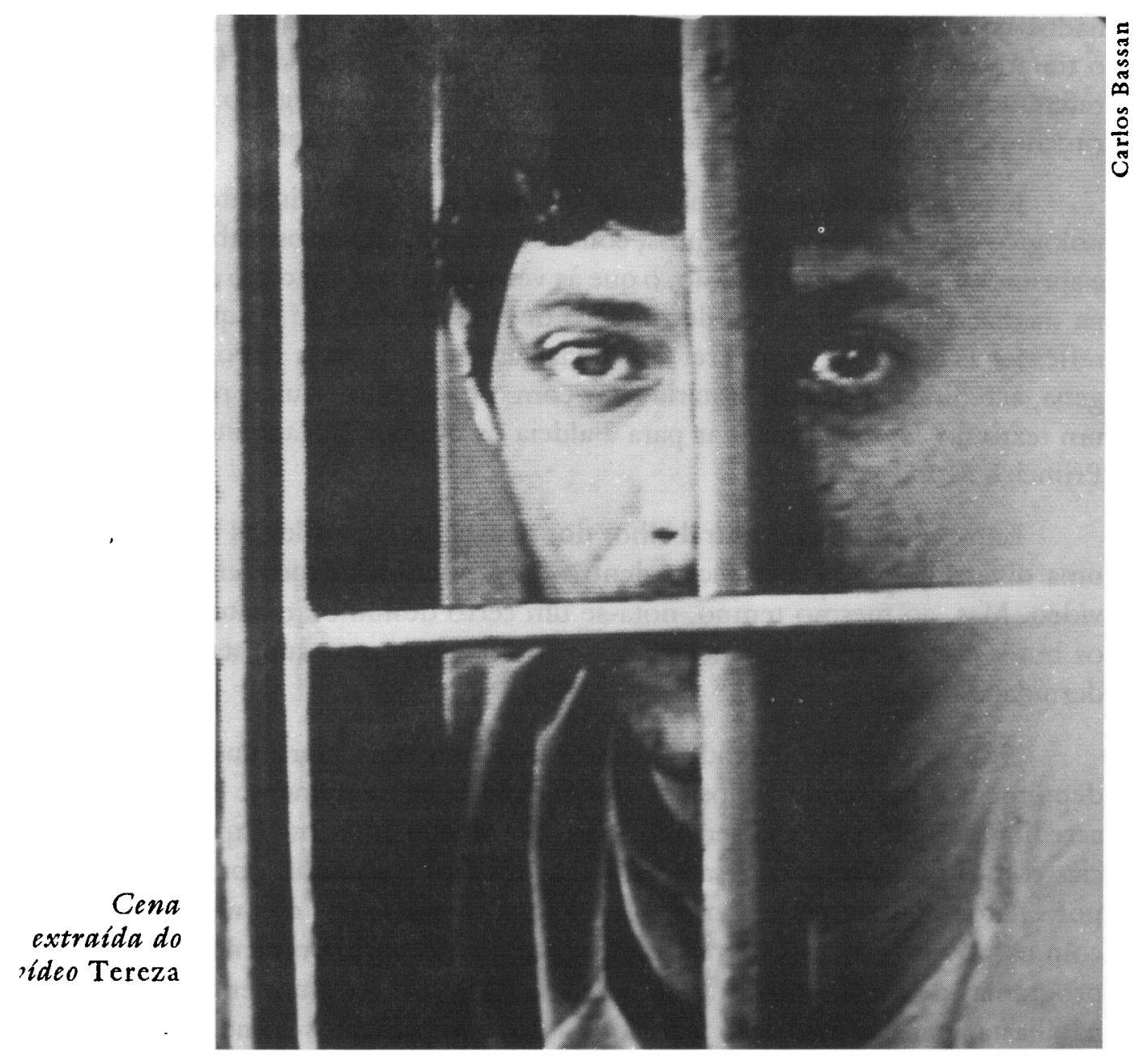

Marcos Ernesto Rogatto é jornalista, mestrando. no Departamento de Multimeios do Instituto de Artes da Universidade de Campinas e produtor independente de vídeo (Stúdio Eletrônico, Campinas, SP, Tel. (0192) 523011).

O vídeo Tereza (termo que no código dos presidiáros tem vários significados, entre eles o de uma espécie de corda utilizada para fugas) foi realizado entre maio e outubro de 1992, no $5^{\circ}$ Distrito Policial e na Penitenciária de Segurança Máxima de Campinas. $O$ trabalho contou com o Prêmio Estímulo da Secretaria de Cultura de Campinas e conquistou as seguintes premiaçōes: Melhor Documentário - VI Fest Vídeo de Porto Alegre, 1992; XVI Guarnicê de Vídeo do Maranhão - Melhor Edição e Direção, 1993; XX Jornada Internacional de Cinema e Vídeo da Bahia - Melhor Vídeo, 1993; IX Rio Cine Festival - Melhor Vídeo Média Duraçăo, 1993; Forumbhzvídeo - Prêmio Especial do Jurí e Prêmio Juri Popular, 1993; I Festival Vídeo de Presidente Prudenter - Melhor Vídeo em Tema Livre, 1994. 